\title{
Long-term safety and tolerability of aripiprazole lauroxil in patients with schizophrenia
}

\author{
Henry A. Nasrallah iD , ${ }^{\prime *}$ Ralph Aquila, ${ }^{2}$ Yangchun Du, ${ }^{3}$ Arielle D. Stanford, ${ }^{3}$ \\ Amy Claxton, ${ }^{3}$ and Peter J. Weiden (iD ${ }^{3}$
}

\footnotetext{
${ }^{1}$ Department of Psychiatry and Behavioral Neuroscience, Saint Louis School of Medicine, St. Louis, Missouri, USA

${ }^{2}$ Fountain House, New York City, New York, USA

${ }^{3}$ Clinical Development and Medical Affairs, Alkermes, Inc., Waltham, Massachusetts, USA
}

Objective. Safety and tolerability of long-term treatment with the long-acting antipsychotic aripiprazole lauroxil (AL) were evaluated in patients with schizophrenia.

Methods. This was an international, multicenter, phase 3, 52-week safety study of 2 fixed doses of AL (441 mg or $882 \mathrm{mg}$ intramuscular every 4 weeks). Safety endpoints included adverse events (AEs) and extrapyramidal symptoms (EPS) including akathisia, injection-site reactions (ISRs), and clinically relevant changes in metabolic and endocrine values.

Results. Of 478 patients entering this study, $236(49 \%)$ continued from a previous 12-week, phase 3 efficacy study of $\mathrm{AL}$, and $242(51 \%)$ were newly enrolled. Overall, $77 \%$ and $23 \%$ of patients received $\mathrm{AL} 882 \mathrm{mg}(\mathrm{N}=368)$ and $441 \mathrm{mg}$ $(\mathrm{N}=110)$, respectively. AEs occurred in $50.4 \%$ of patients; most were mild $(28.7 \%)$ or moderate $(18.2 \%)$. The most common AEs were insomnia (8.4\%) and increased weight (5.0\%). Akathisia was reported as an AE in $3.8 \%$ of the overall population, with higher rates in patients initiating AL on study entry than those continuing on AL. EPS-related AEs occurred in $9.4 \%$ of patients, and AEs related to metabolic parameters were reported in $4.6 \%$ of patients. Weight gain was minimal $(0.8 \mathrm{~kg})$, and no clinically relevant changes were observed for metabolic parameters. The overall incidence of ISRs was $3.8 \%$; most were associated with the initial injections in patients receiving their first injection in this study.

Conclusion. Long-term treatment with AL is generally well tolerated, with a safety profile consistent with that of oral aripiprazole. It is a suitable option for patients with schizophrenia.

Received 22 December 2017; Accepted 3 May 2018; First published online 15 August 2018

* Address for correspondence: Henry A. Nasrallah, MD, Department of Psychiatry and Behavioral Neuroscience, Saint Louis School of Medicine, 1438 S. Grand Boulevard, St. Louis, MO 63104, USA. (Email: hnasral@slu.edu)

ClinicalTrials.gov identifier: NCT01626456; EudraCT Number: 2012-003996-20.

This study was sponsored by Alkermes, Inc., Waltham, MA, USA. Funding for editorial support was provided by Alkermes, Inc., Waltham, MA, USA.

Study results have been presented as a poster at the American Psychiatric Association Annual Meeting, May 20-24, 2017, San Diego, CA, USA, and the American Society of Clinical Psychopharmacology Annual Meeting, May 29-June 2, 2017, Miami, FL, USA.

The authors thank all the patients and investigators who participated in and contributed to this study. The authors thank Drs. Robert Risinger and Chih-Chin Liu (both formerly of Alkermes, Inc.) for their contributions to the analyses of the study. Medical writing and editorial support for the preparation of this manuscript (under the guidance of the authors) was provided by Karen Yee, PhD (ApotheCom, UK).
Key words: Akathisia, aripiprazole lauroxil, extrapyramidal symptoms, injection-site reactions, long-acting injectable antipsychotic, long-term study, metabolic parameters, prolactin, safety, tolerability.

\section{Introduction}

Long-term maintenance treatment with antipsychotic medication is critical for the prevention of relapse and the mitigation of functional deterioration. ${ }^{1-3}$ Antipsychotic medications are associated with a range of adverse events (AEs), with specific risks determined by a range of factors, including duration of exposure, dose, and class of medication prescribed. In general, high-potency conventional antipsychotics have higher rates of neurologic AEs, such as antipsychotic-induced parkinsonism or tardive dyskinesia, whereas some of the atypical antipsychotics are more often associated with weight gain and metabolic problems. ${ }^{4-8}$ These neurologic and metabolic AEs are associated with 
increased burden and impact on medication adherence, with the latter AEs potentially contributing to increased cardiovascular risk, morbidity, and mortality. ${ }^{9-11}$

The risks associated with antipsychotics have been extensively studied, including the relative risks for most of the available oral antipsychotics. ${ }^{12}$ Additional questions regarding the long-term safety of long-acting antipsychotics compared with their oral counterparts arise because of the relatively longer persistence of medication in the plasma, which represents the basis of this therapeutic modality. This is a potential source of concern if the medication has to be discontinued because of treatment-emergent AEs. Thus, it is important to have a comprehensive source of information pertaining to long-term safety (in terms of onset, duration, and extent of AEs) when evaluating the risk-benefit profile for any long-acting antipsychotics.

Aripiprazole lauroxil (AL) is a novel, long-acting injectable atypical antipsychotic indicated for the treatment of adults with schizophrenia. ${ }^{13}$ The efficacy, safety, and tolerability of AL for the treatment of acute exacerbation of symptoms in patients with schizophrenia were previously demonstrated in a pivotal 12 -week phase 3 study comparing 2 dose regimens of $\mathrm{AL}$ (441 $\mathrm{mg}$ and $882 \mathrm{mg}$ every 4 weeks [q4wk]) with placebo (hereafter known as the 12-week efficacy study). ${ }^{14,15}$ A 52-week, open-label extension study was subsequently carried out to evaluate the long-term safety and therapeutic effect of AL in patients with schizophrenia. A post hoc analysis of this study demonstrated the durability of therapeutic effect with $\mathrm{AL}$ in a subgroup of patients who entered the 52-week study after successful treatment with 1 of the 2 active AL doses in the 12-week efficacy study. ${ }^{16}$ However, a detailed report of full safety results of the entire safety population has not been published. In this article, we present a comprehensive summary of the safety results of the 52-week, open-label study of $\mathrm{AL}$ in patients with schizophrenia.

\section{Methods}

This was an international, multicenter, 52-week, phase 3 safety study (ClinicalTrials.gov identifier, NCT01626456; EudraCT Number, 2012-003996-20) conducted during the period June 2012-April 2015. The study was conducted in accordance with the Declaration of Helsinki and with Good Clinical Practice Guidelines agreed by the International Conference on Harmonisation, 1997. The study protocol, amendments, and informed consent forms were approved by an independent ethics committee/institutional review board for each site. All patients provided written informed consent before entering the study.

\section{Patients}

Eligible patients were adults between 18 and 70 years with a primary diagnosis of schizophrenia as defined by the Diagnostic and Statistical Manual of Mental Disorders (Fourth Edition, Text Revision) and who previously had a clinically significant beneficial response to treatment with an antipsychotic medication other than clozapine.

Study participants constituted 2 groups of patients: (1) those who had completed the 12-week efficacy study (ClinicalTrials.gov identifier: NCT01469039; EudraCT Number: 2012-003445-15) ${ }^{14}$ and had agreed to continue into the 52-week safety study and (2) newly recruited de novo outpatients who were prescribed a first-line oral antipsychotic before they entered the 52-week safety study (Figure 1).

Patients who continued from the 12-week efficacy study had previously received 3 injections of either placebo or active AL (441 mg or $882 \mathrm{mg}$ ) q4wk, depending on randomization.

De novo patients were clinically stable (defined as no hospital admission for at least 3 months and Clinical Global Impression-Severity scale score $\leq 3$ [mild] at screening), were receiving a stable dose of oral antipsychotic medication, and would potentially benefit from conversion to an extended-release injectable medication. Medical and psychiatric comorbidity exclusion criteria for de novo patients were similar to those previously described for patients from the 12 -week efficacy study. ${ }^{14}$

\section{2-week safety study design}

The aim of this study was to evaluate the safety and tolerability of long-term treatment with $\mathrm{AL}$ in patients with stable schizophrenia. Patients in this study received up to 13 doses of $\mathrm{AL}$ administered by gluteal injection every 4 weeks over a 52 -week treatment period.

Initial treatment steps depended on how patients entered the study. Patients entering this study from the 12-week efficacy study had already received 3 injections of randomized study medication ( 1 of 2 fixed doses of AL [441 mg or $882 \mathrm{mg}$ ] or volume-matched placebo injection). Patients previously assigned to the active (blinded) $441 \mathrm{mg}$ or $882 \mathrm{mg}$ AL treatment arm continued on their assigned AL dose. Patients previously assigned to the placebo arm started active AL at a fixed dose of either $441 \mathrm{mg}$ or $882 \mathrm{mg}$ q4wk based on the volume of their previous placebo injection (which had been volumematched to either $441 \mathrm{mg}$ or $882 \mathrm{mg}$ AL injection). Patients in this group therefore received their first dose of active AL on entry into the current study. All patients also received a blinded oral study drug (either $15 \mathrm{mg}$ aripiprazole or placebo) daily for the first 3 weeks (ie, 21 days) upon entry into the study. Patients who previously received placebo now received active oral aripiprazole, whereas patients who previously received AL (and concomitant oral aripiprazole for 21 days accordingly in the 12 -week efficacy study) received 


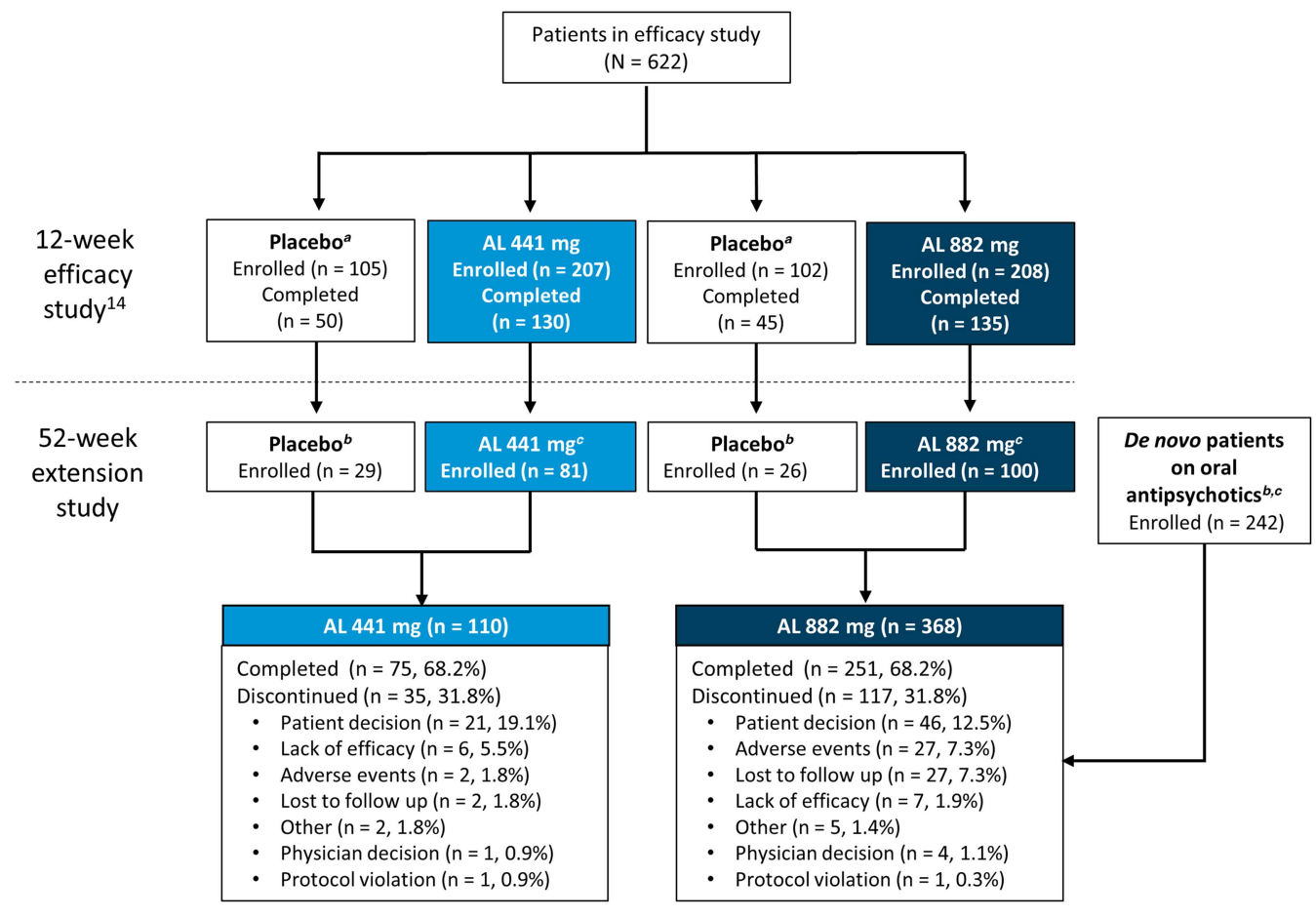

FIGURE 1. Patient disposition.

AL, aripiprazole lauroxil.

${ }^{a}$ Matched low-volume/high-volume placebo.

${ }^{b}$ Patients received active AL for the first time (with concomitant daily oral aripiprazole in the first 3 weeks) in the current 52-week study. Baseline assessments for weight and laboratory metabolic and endocrine parameters were defined as the last nonmissing value on or before the date of each patient's first active AL administration in the current study.

${ }^{c}$ Patients continued to receive active AL (with concomitant daily oral placebo in the first 3 weeks) in the current 52-week study. Baseline assessments for weight and laboratory metabolic and endocrine parameters were defined as the last nonmissing value on or before the date of each patient's first active AL administration in the 12-week efficacy study.

${ }^{d}$ Patients with schizophrenia stabilized on oral antipsychotics with no previous exposure to AL.

placebo capsules. This method was necessary to maintain blinding of treatment assignment in the 12-week efficacy study, which was still ongoing at the time the patients entered the 52-week study.

Following screening and enrollment, de novo patients received their first dose of $\mathrm{AL}(882 \mathrm{mg})$. They also received daily oral aripiprazole supplementation for the first 21 days while being tapered off their current oral antipsychotic (which had to be fully discontinued by the time of their second $\mathrm{AL}$ injection visit 4 weeks later). These patients continued to receive AL $882 \mathrm{mg}$ every 4 weeks thereafter. Further details of this patient population and a post hoc analysis of the clinical outcomes of the initial 12-week crossover period have been reported in a separate publication. ${ }^{17}$

\section{Study assessments}

Safety assessments included the following: AE assessment, injection-site examination, vital signs and weight measurement, completion of abnormal movement scales, laboratory tests, and 12-lead electrocardiogram.
Selected AEs of special interest, including weight gain, metabolic parameters, and extrapyramidal symptoms (EPS; here defined broadly to cover akathisia, dyskinesia, dystonia, and Parkinson-like events), were monitored based on class effects observed with oral aripiprazole and other atypical antipsychotics. Parkinson-like events included tremors, extrapyramidal disorders, parkinsonism, drooling, and dysphonia. EPS were also assessed using the Simpson-Angus Scale (SAS), Abnormal Involuntary Movement Scale (AIMS), and Barnes Akathisia Rating Scale (BARS). Safety assessments were carried out at every visit during the treatment period. Injectionsite reactions (ISRs) were assessed at each visit and were reported as AEs by type (pain or other) and severity (mild, moderate, or severe).

A secondary outcome of interest was psychiatric hospitalizations (which were not automatically listed as a serious $\mathrm{AE}$ ). Hospitalization rates were summarized and compared during the 12-, 9-, 6-, and 3-month periods before and after treatment. For patients who previously received $\mathrm{AL}$, the full pretreatment period was the 12-month period before the first dose of AL in the 
12-week efficacy study, and the full posttreatment period was the 12-month period starting after the first dose of $\mathrm{AL}$ in the current study (the 3-month AL treatment period in the 12-week efficacy study was excluded). For de novo patients and patients who previously received placebo, the full pretreatment and posttreatment periods were the 12-month periods before and after the first dose of AL in the current study, respectively.

\section{Statistical analysis}

Safety analyses were assessed in all patients who received at least 1 dose of AL. Analyses were descriptive, including mean, standard deviation (SD), and mean change from baseline to the last recorded value obtained during the treatment period.

AEs were reported for the duration of the 52-week treatment period for all patients. Certain AEs-notably akathisia and ISRs-have been associated with the first few weeks of AL initiation. ${ }^{14}$ As such, additional post hoc subgroup analyses (by previous treatment) were carried out in certain instances to examine the association between AEs and initiation of drug or injections. All data were presented without additional formal statistical comparisons.

For all patients, baseline assessments for weight and laboratory metabolic and endocrine parameters were defined as the last nonmissing value on or before the date of the first active AL administration. Hence, for patients who previously received $\mathrm{AL}$, these would be values at the start of the 12-week efficacy study. In contrast, baseline values for patients who previously received placebo in the 12-week efficacy study would be values at the start of the current 52-week study; this also applied to the de novo patients.

\section{Results}

\section{Patients}

In total, 478 patients received at least 1 dose of active $\mathrm{AL}$ in this 52 -week safety study, with $76.9 \%(\mathrm{n}=368)$ of patients receiving the $882 \mathrm{mg}$ dose and $23.2 \%(\mathrm{n}=110)$ receiving the $441 \mathrm{mg}$ dose. Figure 1 describes the lead-in status of the patients (either continuing from the 12 -week efficacy study or de novo) before enrollment in the current study and the disposition of the patients according to the $2 \mathrm{AL}$ dose groups. Patient demographics and baseline characteristics were comparable across all groups (presented by lead-in treatment; Table 1). Most patients were male $(57.5 \% ; \mathrm{n}=275)$ and white $(63.8 \% ; \mathrm{n}=305)$; the median age of the patients was 39.4 years.

In total, $68.2 \%(\mathrm{n}=362)$ of all patients completed the study (Figure 1). Overall, $75.5 \%$ of patients received $\geq 9$ injections, and $68.8 \%$ of patients received 13 injections of $\mathrm{AL}$ over 52 weeks. The most common reason for early termination was withdrawal of consent by the patient $(14.0 \% ; \mathrm{n}=67)$. In total, 15 patients received open-label oral antipsychotic medication for a psychotic flare-up during the course of the study; 10 patients continued in the study following resolution of symptoms, while 5 patients were discontinued from the study.

TABLE 1. Baseline characteristics

\begin{tabular}{|c|c|c|c|c|c|c|}
\hline \multirow[b]{2}{*}{ Pre-enrollment status } & \multicolumn{2}{|c|}{ Inpatient treatment in 12-week efficacy study } & \multicolumn{2}{|c|}{ Inpatient treatment in 12-week efficacy study } & \multirow{2}{*}{$\begin{array}{c}\text { Stable outpatient } \\
\text { (de novo) } \\
\text { Oral } \\
\text { antipsychotics } \\
n=242\end{array}$} & \multirow[b]{3}{*}{$\begin{array}{c}\text { Total } \\
\mathrm{N}=478\end{array}$} \\
\hline & $\begin{array}{c}\text { Placebo } \\
\text { (3 doses) } \\
n=29\end{array}$ & $\begin{array}{c}\text { AL } 441 \mathrm{mg} \\
\text { (3 doses) } \\
\mathrm{n}=81\end{array}$ & $\begin{array}{c}\text { Placebo } \\
\text { (3 doses) } \\
n=26\end{array}$ & $\begin{array}{c}\text { AL } 882 \mathrm{mg} \\
\text { (3 doses) } \\
n=100\end{array}$ & & \\
\hline Dosage & \multicolumn{2}{|c|}{$\begin{array}{c}\text { AL } 441 \mathrm{mg}^{a} \mathrm{q} 4 \mathrm{wk} \\
\mathrm{N}=110\end{array}$} & & $\begin{array}{c}\text { AL } 882 \mathrm{mg}^{b} \mathrm{q} 4 \mathrm{wk} \\
\mathrm{N}=368\end{array}$ & & \\
\hline Age, years & $36.3(11.4)$ & $38.8(10.7)$ & $38.4(12.4)$ & $38.9(11.4)$ & $40.3(11.9)$ & $39.4(11.6)$ \\
\hline Sex, male, n (\%) & $17(58.6)$ & $48(59.3)$ & $15(57.7)$ & $64(64.0)$ & $131(54.1)$ & $275(57.5)$ \\
\hline \multicolumn{7}{|l|}{ Race, n (\%) } \\
\hline White & $23(79.3)$ & $54(66.7)$ & $13(50.0)$ & $64(64.0)$ & $151(62.4)$ & $305(63.8)$ \\
\hline Black or African-American & $2(6.9)$ & $11(13.6)$ & $7(26.9)$ & $13(13.0)$ & $59(24.4)$ & $92(19.2)$ \\
\hline Asian & $4(13.8)$ & $16(19.8)$ & $6(23.1)$ & $23(23.0)$ & $30(12.4)$ & 79 (16.5) \\
\hline Native Hawaiian or Other Pacific Islander & 0 & 0 & 0 & 0 & $2(0.8)$ & $2(0.4)$ \\
\hline BMI, $\mathrm{kg} / \mathrm{m}^{2}$ & $26.9(5.0)$ & $26.6(4.8)$ & $25.6(4.9)$ & $26.2(5.4)$ & $27.6(5.4)$ & $27.0(5.3)$ \\
\hline Weight, kg & 77.7 (17.2) & 74.6 (15.3) & $73.0(22.0)$ & 75.8 (19.7) & 80.8 (17.7) & 78.1 (18.1) \\
\hline
\end{tabular}


TABLE 2. Overview of AES

\begin{tabular}{|c|c|c|c|}
\hline Parameter & $\begin{array}{c}\text { AL } 441 \mathrm{mg} q 4 w k \\
\begin{array}{c}\mathrm{N}=110 \\
\mathrm{n}(\%)\end{array}\end{array}$ & $\begin{array}{c}\text { AL } 882 \mathrm{mg} q 4 w k \\
\mathrm{~N}=368 \\
\mathrm{n}(\%)\end{array}$ & $\begin{array}{c}\text { Total } \\
N=478 \\
n(\%)\end{array}$ \\
\hline Any AE & $51(46.4)$ & $190(51.6)$ & $241(50.4)$ \\
\hline Any drug-related AE & $29(26.4)$ & $112(30.4)$ & $141(29.5)$ \\
\hline \multicolumn{4}{|l|}{ AE by highest severity } \\
\hline Mild & 37 (33.6) & $100(27.2)$ & $137(28.7)$ \\
\hline Moderate & $12(10.9)$ & $75(20.4)$ & $87(18.2)$ \\
\hline Severe & $2(1.8)$ & $15(4.1)$ & $17(3.6)$ \\
\hline Any SAE & 0 & $15(4.1)$ & $15(3.1)$ \\
\hline $\begin{array}{l}\text { Any SAE leading to } \\
\text { discontinuation }\end{array}$ & 0 & $10(2.7)$ & $10(2.1)$ \\
\hline Any SAE leading to death & 0 & $2(0.5)$ & $2(0.4)$ \\
\hline Any drug-related SAE & 0 & $3(0.8)$ & $3(0.6)$ \\
\hline $\begin{array}{l}\text { Any AE leading to } \\
\text { discontinuation }\end{array}$ & $1(0.9)$ & $27(7.3)$ & $28(5.9)$ \\
\hline \multicolumn{4}{|l|}{$\begin{array}{l}\text { AEs in } \geq 2 \% \text { of all } \\
\text { patients }^{b}\end{array}$} \\
\hline Insomnia & $3(2.7)$ & $37(10.1)$ & $40(8.4)$ \\
\hline Weight increased & $7(6.4)$ & $17(4.6)$ & $24(5.0)$ \\
\hline Anxiety & $4(3.6)$ & $17(4.6)$ & $21(4.4)$ \\
\hline Injection site pain & $1(0.9)$ & $17(4.6)^{c}$ & $18(3.8)$ \\
\hline Akathisia & $1(0.9)$ & $17(4.6)$ & $18(3.8)$ \\
\hline Headache & $7(6.4)$ & $11(3.0)$ & $18(3.8)$ \\
\hline Schizophrenia & $4(3.6)$ & $12(3.3)$ & $16(3.3)$ \\
\hline Nasopharyngitis & $4(3.6)$ & $10(2.7)$ & $14(2.9)$ \\
\hline Weight decreased & $3(2.7)$ & $9(2.4)$ & $12(2.5)$ \\
\hline Tremor & $1(0.9)$ & $11(3.0)$ & $12(2.5)$ \\
\hline \multicolumn{4}{|c|}{ AEs associated with extrapyramidal symptoms } \\
\hline Any & $5(4.5)$ & $40(10.9)$ & $45(9.4)$ \\
\hline Akathisia & $1(0.9)$ & $17(4.6)$ & $18(3.8)$ \\
\hline Dsykinesia & 0 & $2(0.5)$ & $2(0.4)$ \\
\hline Dystonia & $3(2.7)$ & $5(1.4)$ & $8(1.7)$ \\
\hline Parkinson-like events & $2(1.8)$ & $20(5.4)$ & $22(4.6)$ \\
\hline Restlessness & 0 & $2(0.5)$ & $2(0.4)$ \\
\hline
\end{tabular}

AE, adverse event; AL, aripiprazole lauroxil; SAE, serious adverse event; q4wk, every 4 weeks.

${ }^{a}$ One patient who discontinued because of weight gain was not included because the AE occurred before the first injection in the long-term study.

${ }^{b}$ Patients who experienced more than one AE in any category were counted only once in that category.

${ }^{c} 16$ of 17 (94\%) events were reported in de novo patients who received their first injection in this study.

\section{Safety}

Adverse events

Overall, AEs during the treatment period were reported in $50.4 \%(\mathrm{n}=241)$ of patients; most were mild or moderate in intensity (Table 2). Serious AEs (SAEs) were reported in $3.1 \%(n=15)$ of patients, leading to study discontinuation in 10 of the 15 patients (2.1\%). All SAEs occurred in the AL $882 \mathrm{mg}$ group. Two SAEs resulted in death, the first due to cardiopulmonary arrest following an accidental gunshot wound (assessed by investigator as probably not related to the study drug) and the second due to a suicide associated with worsening of schizophrenia symptoms (assessed by investigator as possibly related to the study drug).

AEs leading to discontinuation were reported in $5.9 \%$ $(\mathrm{n}=28)$ of the total population and occurred more frequently among patients in the AL $882 \mathrm{mg}$ group than in the $441 \mathrm{mg}$ group $(7.3 \%$ vs $0.9 \%$, respectively) (Table 2). The most common AEs leading to discontinuation were reported under the system organ class of "psychiatric disorders" (including schizophrenia as the most frequent; $n=11)$, which occurred in $3.6 \%(n=17)$ of the total population, likely representing a worsening of the primary disease. Of these 17 patients, 16 were from the AL $882 \mathrm{mg}$ group. These safety results were also analyzed by lead-in treatment on entry into the current study (Table S1, available online in the Supplementary Material). In total, 12 of the 15 patients in the AL $882 \mathrm{mg}$ group who experienced a SAE were patients without previous exposure to $\mathrm{AL}$ who started active $\mathrm{AL}$ (along with 21 days of oral aripiprazole supplementation) upon study entry (ie, the prior-placebo and de novo groups). Similarly, the majority of patients on AL $882 \mathrm{mg}$ who discontinued due to an $\mathrm{AE}$ ( 22 of 27 patients) were in this patient group.

The most frequently reported AEs overall were insomnia $(8.4 \%)$, weight increased $(5.0 \%)$, and anxiety (4.4\%). Similar incidences of AEs were reported in the individual doses $(46.4 \%$ and $51.6 \%$ in the $441 \mathrm{mg}$ and $882 \mathrm{mg}$ AL groups, respectively). Patients receiving $882 \mathrm{mg}$ had a higher incidence of insomnia, injectionsite pain, akathisia, and tremor than patients receiving $441 \mathrm{mg}$ (Table 2), possibly because a higher proportion of patients in the $882 \mathrm{mg}$ group than the $441 \mathrm{mg}$ group started AL on study entry. Results of post hoc analysis examining the association between akathisia and ISRs with the initiation of $\mathrm{AL}$ are presented in the following sections.

\section{Adverse events of interest}

Injection-site reactions. The overall incidence of ISRs for the entire safety population was $4.8 \%(n=23 / 491)$; most of the ISRs were reported as injection-site pain events $(n=18 / 23 ; 78 \%)$, and of these, 14 events were considered mild. A higher frequency of injection-site pain was observed in the AL $882 \mathrm{mg}$ group $(4.6 \% ; \mathrm{n}=17)$ than in the AL $441 \mathrm{mg}$ group $(0.9 \% ; \mathrm{n}=1)$ (Table 2$)$. The mean duration of injection-site pain was 6.3 days, and the median was 3.0 days $(n=18)$.

Examination of the pattern of ISR occurrence by leadin treatment (Table 3) showed that most ISRs were reported in the de novo patients who received their first injection in this study $(\mathrm{N}=242)$, with $8.3 \%(\mathrm{n}=20)$ reporting $\geq 1$ event; injection-site pain was the most common ISR. Patients entering the current study after 
TABLE 3. Summary of ISRs by the associated injection and lead-in treatment group

De novo ${ }^{a}$ Prior $\mathrm{AL}^{b}$ Prior placebo ${ }^{c}$ Total

$\mathrm{N}=242 \quad \mathrm{~N}=181 \quad \mathrm{~N}=55 \quad(\mathrm{~N}=478)$

\begin{tabular}{|c|c|c|c|c|}
\hline \multicolumn{5}{|l|}{ ISRs by injection number } \\
\hline \multicolumn{5}{|l|}{ First injection } \\
\hline Any ISR & 13/242 (5.4) & 0 & 0 & 13/478 (2.7) \\
\hline \multicolumn{5}{|l|}{ Second injection } \\
\hline Any ISR & 9/225 (4.0) & 0 & 0 & 9/445 (2.0) \\
\hline \multicolumn{5}{|l|}{ Third injection } \\
\hline Any ISR & $8 / 218(3.7)$ & 0 & 0 & 8/433 (1.8) \\
\hline \multicolumn{5}{|l|}{ All injections } \\
\hline Any ISR & 20/242 (8.3) 3 & /181 (1.7) & 0 & $23 / 478^{e}(4.8)$ \\
\hline Injection-site pain ${ }^{d}$ & $16 / 20(80.0)$ & $2 / 3(66.7)$ & 0 & $18 / 23^{f}(78.3)$ \\
\hline
\end{tabular}

AL, aripiprazole lauroxil; ISR, injection-site reaction. The number of patients experiencing any ISRs from the fourth injection onward ranged from 0 to 5 per injection. All values are expressed as $\mathrm{n} / \mathrm{m}(\%)$, where $\mathrm{m}$ represents the number of evaluable patients, unless otherwise indicated.

${ }^{a}$ The first injection in the long-term study was the first exposure to AL (882 mg).

${ }^{b}$ Previously received 3 injections of AL in the acute-phase study; the first injection in the long-term study was the fourth exposure to AL (441 or $882 \mathrm{mg}$ ).

${ }^{C}$ Previously received 3 injections of placebo in the acute-phase study; the first injection in the long-term study was the first exposure to AL (441 or $882 \mathrm{mg}$ ).

${ }^{d}$ Calculated as percentage of any ISRs.

${ }^{e}$ Some patients reported multiple ISRs over the course of the study.

${ }^{f}$ Some patients reported multiple injection-site pain events over the course of the study; of 18 patients who reported injection-site pain, 14, 3, and 1 patients experienced a maximum severity of mild, moderate, and severe, respectively.

previously receiving 3 injections in the 12 -week efficacy study (AL $[\mathrm{N}=181]$ and placebo $[\mathrm{N}=55])$ had a lower incidence of ISRs $(1.7 \%[n=3]$ and $0 \%$ of patients, respectively) than de novo patients (Table 3 ). Most ISRs were associated with the initial injections and decreased in frequency at subsequent injection visits (Table 3).

Extrapyramidal symptoms. Overall, 9.4\% ( $\mathrm{n}=45)$ of patients reported AEs associated with EPS (here broadly defined to encompass akathisia, dyskinesia, dystonia, Parkinson-like events, and restlessness), at an incidence of $4.5 \%(\mathrm{n}=5)$ for the $441 \mathrm{mg}$ group and $10.9 \%(\mathrm{n}=40)$ for the $882 \mathrm{mg}$ group (Table 2). None of the events were severe or serious. Three patients in the $882 \mathrm{mg}$ group discontinued the study because of EPS-associated AEs (2 akathisia, 1 Parkinson-like event).

With regard to individual EPS symptoms, the frequencies of dyskinesia and dystonia were low and similar for both dose groups (Table 2). Higher incidences of akathisia $(4.6 \%$ vs $0.9 \%)$ and Parkinson-like events $(5.4 \%$ vs $1.8 \%)$ were reported in the AL $882 \mathrm{mg}$ group than in the AL $441 \mathrm{mg}$ group (Table 2). To explore possible reasons for the apparent differences, the incidences of akathisia and other EPS were investigated in patients subgrouped by previous AL exposure
(Table S2). This analysis showed that most of the akathisia AEs (83\%; 15 of 18 events) occurred in the subgroup of patients who initiated AL and aripiprazole supplementation when they entered this safety study. Most of the akathisia events in this study occurred early during treatment: $3.1 \%(n=15)$ of patients in the first 3 months of the study, $0.2 \%(\mathrm{n}=1)$ in the following 3 months, and $0.8 \%(n=3)$ of patients in the subsequent 3 months. No akathisia events were reported after the ninth month.

The incidence of Parkinson-like events did not seem to be related to whether a patient started AL at the time of study entry because the incidence was comparable in all 3 subgroups: $5.0 \%, 3.9 \%$, and $5.5 \%$ in the de novo, prior AL, and prior-placebo subgroups, respectively (Table S2).

Overall, the changes in the structured abnormal movement scales (SAS for antipsychotic-induced Parkinsonism, BARS for akathisia, and AIMS for dyskinesia) were minimal, and the mean total score remained relatively constant over time in all treatment groups for all 3 scales.

\section{Body weight and body mass index}

Long-term exposure to AL resulted in a small mean increase in body weight $(0.8 \mathrm{~kg})$ and body mass index (BMI) score $(0.3)$ from baseline to the last recorded assessment overall (Table 4). Of the 351 patients who received treatment throughout the 52 weeks, $25 \mathbf{( 7 . 1 \% )}$ and $12(3.4 \%)$ had weight gains of $>10 \mathrm{~kg}$ and $>15 \mathrm{~kg}$, respectively. Potentially clinically significant increases in body weight of $\geq 7 \%$ occurred in $18.4 \% \quad(n=88)$ of patients, whereas $\geq 7 \%$ decreases in body weight occurred in $12.3 \%(n=59)$ of patients (Table 4$)$. AEs of increased weight were reported in $6.4 \%(\mathrm{n}=7)$ and $4.6 \%$ $(\mathrm{n}=17)$ of patients in the $441 \mathrm{mg}$ and $882 \mathrm{mg}$ groups, respectively (Table 2 ).

\section{Glycemic control and lipid parameters}

Long-term treatment with $\mathrm{AL}$ was associated with relatively modest increases in fasting glucose and glycated hemoglobin $\left(\mathrm{HbA}_{1 \mathrm{c}}\right)$ levels (Table 4). No clinically meaningful changes were observed for any glycemic-control or lipid parameters (Table 4). AEs related to metabolic parameters were reported in $3.6 \%$ $(\mathrm{n}=4)$ and $4.9 \%(\mathrm{n}=18)$ of patients in the AL $441 \mathrm{mg}$ and $882 \mathrm{mg}$ groups, respectively. The most frequently reported $\mathrm{AE}$ related to metabolic parameters in the $441 \mathrm{mg}$ group was increased $\mathrm{HbA}_{1 \mathrm{c}}(\mathrm{n}=3)$; the most frequently reported AEs in the $882 \mathrm{mg}$ group were hyperglycemia $(\mathrm{n}=4)$, increased $\mathrm{HbA}_{1 \mathrm{c}}(\mathrm{n}=3)$, and diabetes mellitus $(n=3)$. Type 2 diabetes mellitus was reported in 1 and 2 patients in the $441 \mathrm{mg}$ and $882 \mathrm{mg}$ groups, respectively. $\mathrm{An} \mathrm{AE}$ of glucosuria was also 
TABLE 4. Baseline values and changes in body weight, BMI, metabolic and lipid parameters, and prolactin

\begin{tabular}{|c|c|c|c|}
\hline Parameter $^{a}$ & $\begin{array}{l}\text { AL } 441 \mathrm{mg} \text { q4wk } \\
\quad \mathrm{N}=110\end{array}$ & $\begin{array}{c}\text { AL } 882 \mathrm{mg} \text { q4wk } \\
\mathrm{N}=368\end{array}$ & $\begin{array}{c}\text { Total } \\
\mathrm{N}=468\end{array}$ \\
\hline \multicolumn{4}{|l|}{ Cholesterol, mg/dL } \\
\hline Baseline & $193.9(45.8)$ & $190.8(40.4)$ & $191.5(41.6)$ \\
\hline Change $^{b}$ & $-3.6(37.5)$ & $-3.2(35.4)$ & $-3.3(35.8)$ \\
\hline \multicolumn{4}{|l|}{ HDL cholesterol, mg/dL } \\
\hline Baseline & $49.6(16.1)$ & $52.8(15.3)$ & $52.1(15.5)$ \\
\hline Change $^{b}$ & $1.3(11.9)$ & $0.9(12.4)$ & $1.0(12.3)$ \\
\hline \multicolumn{4}{|l|}{ LDL cholesterol, $\mathrm{mg} / \mathrm{dL}$} \\
\hline Baseline & $112.0(36.3)$ & $111.1(34.6)$ & $111.3(35.0)$ \\
\hline Change $^{b}$ & $-1.1(32.5)$ & $-3.1(29.8)$ & $-2.6(30.4)$ \\
\hline \multicolumn{4}{|l|}{ Triglycerides, $\mathrm{mg} / \mathrm{dL}$} \\
\hline Baseline & $156.3(111.7)$ & $134.0(90.9)$ & $139.1(96.4)$ \\
\hline Change $^{b}$ & $-16.1(89.1)$ & $-2.0(105.3)$ & $-5.3(101.9)$ \\
\hline \multicolumn{4}{|l|}{ Glucose, $\mathrm{mg} / \mathrm{dL}$} \\
\hline Baseline & $91.0(16.6)$ & $92.1(22.3)$ & $91.8(21.1)$ \\
\hline Change $^{b}$ & $0.3(21.0)$ & $1.4(29.2)$ & $1.1(27.5)$ \\
\hline \multicolumn{4}{|l|}{$\mathrm{HbA} A_{1 \mathrm{c}}, \%$ (fasting) } \\
\hline Baseline & $5.4(0.3)$ & $5.5(0.5)$ & $5.5(0.5)$ \\
\hline Change $^{b}$ & $0.1(0.2)$ & $0.1(0.7)$ & $0.1(0.6)$ \\
\hline \multicolumn{4}{|l|}{$\mathrm{BMI}, \mathrm{kg} / \mathrm{m}^{2}$} \\
\hline Baseline & $26.7(4.9)$ & $27.1(5.4)$ & $27.0(5.3)$ \\
\hline Change $^{b}$ & $0.5(2.4)$ & $0.3(1.9)$ & $0.3(2.0)$ \\
\hline \multicolumn{4}{|l|}{ Body weight, $\mathrm{kg}$} \\
\hline Baseline & $75.4(15.8)$ & $78.9(18.7)$ & $78.1(18.1)$ \\
\hline Change $^{b}$ & $1.3(6.9)$ & $0.7(5.5)$ & $0.8(5.9)$ \\
\hline $\begin{array}{l}\text { Increase of } \geq 7 \% \text { at any } \\
\quad \text { postbaseline visit, } n(\%)\end{array}$ & $23(20.9)$ & $65(17.7)$ & $88(18.4)$ \\
\hline $\begin{array}{l}\text { Decrease of } \geq 7 \% \text { at any } \\
\text { postbaseline visit, } n(\%)\end{array}$ & $13(11.8)$ & $46(12.5)$ & $59(12.3)$ \\
\hline \multicolumn{4}{|l|}{ Prolactin, $\mathrm{ng} / \mathrm{mL}$} \\
\hline \multicolumn{4}{|l|}{ Male } \\
\hline Baseline & $11.8(11.5)$ & $13.7(16.9)$ & $13.3(15.8)$ \\
\hline Change $^{b}$ & $-7.6(12.5)$ & $-9.1(15.4)$ & $-8.7(14.7)$ \\
\hline \multicolumn{4}{|l|}{ Female } \\
\hline Baseline & $32.8(47.6)$ & $29.7(38.6)$ & $30.4(40.6)$ \\
\hline Change $^{b}$ & $-19.5(48.7)$ & $-13.7(41.9)$ & $-14.9(43.4)$ \\
\hline
\end{tabular}

$\mathrm{AL}$, aripiprazole lauroxil; BMI, body mass index; $\mathrm{HbA}_{1 \mathrm{c}}$, glycated hemoglobin; HDL, high-density lipoprotein; LDL, low-density lipoprotein; q4wk, every 4 weeks; $\mathrm{SD}$, standard deviation.

${ }^{a}$ Values are expressed as mean (SD) unless otherwise noted.

${ }^{b}$ Change to last postbaseline value during the treatment period.

reported in 1 patient in the $882 \mathrm{mg}$ group. A SAE of hyperglycemia was reported in 1 patient in the $882 \mathrm{mg}$ group, resulting in study discontinuation.

\section{Prolactin}

Overall baseline prolactin levels were 13.3 and $30.4 \mathrm{ng} /$ $\mathrm{mL}$ for male and female patients, respectively, with normal levels defined as 4.0 to $15.2 \mathrm{ng} / \mathrm{mL}$ for males and 4.8 to $23.3 \mathrm{ng} / \mathrm{mL}$ for females. Mean serum prolactin levels decreased from baseline to the last postbaseline assessment in both sexes, with a decrease in mean serum prolactin of $8.7 \mathrm{ng} / \mathrm{mL}$ for males and $14.9 \mathrm{ng} / \mathrm{mL}$ for females overall (Table 4).
The trajectory of prolactin level change is better understood in the context of the patients entering the safety study with prolactin elevations (with potentially clinically significant values defined as $\geq 1$ to $\geq 3$ times the upper limit of normal [ULN]). Overall, 22.5\% $(n=59)$ of males and $34.7 \%(n=68)$ of females had prolactin elevations $\geq 3 \times$ ULN at baseline. Among this subgroup with elevated baseline levels, $72.9 \%$ of males $(n=43)$ and $61.8 \%(\mathrm{n}=42)$ of females had at least 1 follow-up prolactin level within the normal range.

In total, 151 male and 110 female patients had nonpotentially clinically significant prolactin values at baseline. Among these patients, 10 (6.6\%) male and 21 (19.1\%) female patients had potentially clinically significant values at any postbaseline visit that were $\geq 1 \times$ to $\geq 3 \times$ ULN (Table S3). Two female patients had potentially clinically significant values $\geq 3 \times \mathrm{ULN}$, but both completed the study and neither had any AEs associated with prolactin. The proportions of males and females who experienced shifts from normal or low prolactin at baseline to $\geq 3 \times \mathrm{ULN}$ at any postbaseline visit were $5.4 \%$ and $15.6 \%$, respectively. Five (1.4\%) patients in the 882 $\mathrm{mg}$ group (but none in the $441 \mathrm{mg}$ group) reported AEs associated with prolactin; none were considered severe.

\section{Other laboratory or safety measures}

No clinically relevant changes in clinical safety laboratory tests, vital signs, or electrocardiography values were observed.

\section{Hospital admission outcomes}

Fewer patients were admitted to the hospital for psychiatric events in their posttreatment period compared with their corresponding pretreatment period. The crude rates of psychiatric hospital admissions during the 3-, 6-, 9-, and 12-month pretreatment periods were $15.0 \%, 19.7 \%, 27.2 \%$, and $30.7 \%$, respectively, whereas rates during the 3-, 6-, 9-, and 12-month posttreatment periods were $2.0 \%, 3.0 \%, 3.5 \%$, and $3.5 \%$, respectively.

\section{Discussion}

Patients with schizophrenia require ongoing treatment with antipsychotic medication. Thus, evaluating the long-term tolerability and safety of an antipsychotic agent is clearly important when selecting one for maintenance treatment. Results of the current study showed that treatment with $441 \mathrm{mg}$ or $882 \mathrm{mg}$ AL for up to 52 weeks in patients with schizophrenia was well tolerated and had a high completion rate $(68.2 \%)$. In general, the safety and tolerability profile of $\mathrm{AL}$ in the current 52-week study was consistent with that reported in the 12-week efficacy study, demonstrating a low risk 
for metabolic abnormalities and modest weight gain. ${ }^{14,15}$ No new safety events were observed during the 52-week treatment period.

In this study, treatment with $\mathrm{AL} 882 \mathrm{mg}$ was associated with a higher incidence of SAEs, discontinuations due to AEs, insomnia, akathisia, tremor, and injection site pain than treatment with $\mathrm{AL} 441 \mathrm{mg}$. However, interpretation of any apparent dose-related findings should take into account the fact that most $(66 \%)$ patients in the $882 \mathrm{mg}$ group were de novo patients who were not previously exposed to $\mathrm{AL}$ and that a greater proportion of patients in the $882 \mathrm{mg}$ group (72.8\%) compared with patients in the $441 \mathrm{mg}$ group (26.4\%) had their first exposure to $\mathrm{AL}$ in the current study. Hence, AEs that are generally associated with initiation of $\mathrm{AL}$ were captured in disproportionately greater numbers in the $882 \mathrm{mg}$ group compared with the $441 \mathrm{mg}$ group. Indeed, most of the SAEs and discontinuations occurred in this patient population. Overall, the safety profile of $\mathrm{AL}$ was generally consistent with previously reported long-term safety profiles of oral aripiprazole and aripiprazole once-monthly $(400 \mathrm{mg}) \quad$ long-acting injectable. $^{18-20}$

The overall incidence of ISRs in this study was low. As anticipated, ISRs occurred more frequently in the $d e$ novo patients receiving their first $\mathrm{AL}$ injection than in patients from the earlier 12-week efficacy study who were receiving their fourth intramuscular (IM) injection. We were particularly interested in the patients who had previous exposure only to placebo injections and were receiving active $\mathrm{AL}$ for the first time, because this provided an opportunity to investigate the extent to which ISRs are due to injection procedures rather than to the active AL suspension. The observation that no new ISRs were reported in the 55 patients who entered the safety study from the placebo arm of the earlier 12-week efficacy study (and had presumably become accommodated to IM injections) supports the idea that ISRs were associated with the novelty of the initial injections rather than the study drug per se. The incidence of ISRs in the de novo patients $(\mathbf{8 . 3 \%})$ was higher than that reported for the 12-week efficacy study (3.9\% [AL $441 \mathrm{mg}$ ] and $5.8 \%$ [AL $882 \mathrm{mg}]) .{ }^{14}$ As in that study, the rate of ISRs decreased as a function of injection number over time. ${ }^{14}$

Overall, the incidence of broadly defined EPS-related $\mathrm{AEs}$ with $\mathrm{AL}$ was low, and none were considered severe or serious, which is consistent with the known safety profile of aripiprazole. The higher akathisia rates in the $882 \mathrm{mg}$ group compared with the $441 \mathrm{mg}$ group ( $4.6 \%$ vs $0.9 \%$ ) were driven primarily by patients who were receiving $\mathrm{AL}$ for the first time in the study, confirming the association between akathisia and AL initiation (and concomitant oral aripiprazole). As in the 12-week efficacy study, most of the akathisia episodes occurred during the initial phases of the study when concomitant oral aripiprazole was being administered, supporting the idea that the combined exposure of oral aripiprazole and injected $\mathrm{AL}$ might have contributed to the incidence of akathisia. The overall frequency of Parkinson-like events (including tremor) was low $(4.6 \%)$, and was also reported at a higher frequency in the $882 \mathrm{mg}$ group $(5.4 \%)$ than in the $441 \mathrm{mg}$ group (1.8\%). Unlike the akathisia events, these events did not appear to correlate with any particular lead-in treatment in the $882 \mathrm{mg}$ group (Table S1), raising the possibility that the incidence of Parkinson-like events might be dose related.

Consistent with results of the 12-week efficacy study, results of the current study demonstrate that AL caused few clinically relevant metabolic parameter AEs in patients with schizophrenia and that $\mathrm{AL}$ is effective at limiting the pronounced weight gain and other metabolic risks commonly encountered with other antipsychotics. ${ }^{15}$ Increases in mean body weight and BMI index were minimal over the course of the study; in this study, an increase of $\geq 7 \%$ in body weight was observed in $18.4 \%$ of patients over 52 weeks, which compared favorably with results from a 52-week, randomized, double-blind trial evaluating olanzapine, quetiapine, and risperidone (range, 50\%-80\%). ${ }^{21}$ Minimal changes from baseline to last postbaseline assessment were observed for lipid and glycemic parameters and for plasma glucose and $\mathrm{HbA}_{1 \mathrm{c}}$ levels, consistent with observations in other studies of oral aripiprazole. ${ }^{15,19,22,23}$ Treatment with AL was associated with decreased mean prolactin levels below baseline toward the normal range, which is consistent with previous studies of aripiprazole in patients with schizophrenia. ${ }^{15,19,24}$

A limitation of this study was the lack of a placebo group, which limited the ability to attribute any specific outcomes to treatment with $\mathrm{AL}$. In addition, the selective inclusion of patients who successfully completed the 12-week efficacy study may limit the generalizability of the study results because this might have resulted in the preferential selection of a study population who derived benefit from $\mathrm{AL}$ treatment while excluding patients who did not respond or who had adverse reactions to $\mathrm{AL}$ treatment. However, inclusion of newly enrolled (de novo) patients allowed for the evaluation of AL in a nonselected cohort of patients. Evaluation of any apparent dose-related effects in this study should take into account the fact that these patients received their first injection and their first exposure to AL in this study. Finally, the inclusion criteria precluded the possibility of drawing conclusions regarding the tolerability of AL in "first episode" or antipsychoticnaïve patients. As these patients have been shown to display high rates of AEs with antipsychotics, ${ }^{25}$ clinicians might need to bear this in mind when considering $\mathrm{AL}$ treatment for these patients.

The results of this study demonstrate the safety and tolerability of long-term treatment with $\mathrm{AL}$ in patients 
with schizophrenia, with a safety profile consistent with that of oral aripiprazole and with no unexpected safety concerns during the 1-year, long-term study, thus addressing clinical concerns regarding long-term safety with continued AL therapy.

\section{Disclosure}

Henry Nasrallah has the following disclosures: Alkermes, personal fees; Acadia, personal fees; Allergan, personal fees; Boehringer Ingelheim, personal fees; Janssen, personal fees, Lundbeck, personal fees; Neurocrine, personal fees; Otsuka, personal fees; Sunovion, personal fees; Teva, personal fees; Vanda, personal fees; and Forum, personal fees. Ralph Aquila reports personal fees from Alkermes during the conduct of the study, personal fees from Otsuka, personal fees from Sunovion, and personal fees from Janssen, outside the submitted work. Yangchun Du, Arielle Stanford, Amy Claxton, and Peter J. Weiden, are employees of and hold stock in Alkermes.

\section{Supplementary materials}

To view supplementary material for this article, please visit https://doi.org/10.1017/S1092852918001104

\section{REFERENCES:}

1. Hasan A, Falkai P, Wobrock T, et al. World Federation of Societies of Biological Psychiatry (WFSBP) guidelines for biological treatment of schizophrenia, part 2: update 2012 on the long-term treatment of schizophrenia and management of antipsychotic-induced side effects. World J Biol Psychiatry. 2013; 14(1): 2-44.

2. Harvey PD, Loewenstein DA, Czaja SJ. Hospitalization and psychosis: influences on the course of cognition and everyday functioning in people with schizophrenia. Neurobiol Dis. 2013; 53: 18-25.

3. Caseiro O, Pérez-Iglesias R, Mata I, et al. Predicting relapse after a first episode of non-affective psychosis: a three-year follow-up study. J Psychiatr Res. 2012; 46(8): 1099-1105.

4. Correll CU, Manu P, Olshanskiy V, Napolitano B, Kane JM, Malhotra AK. Cardiometabolic risk of second-generation antipsychotic medications during first-time use in children and adolescents. JAMA. 2009; 302(16): 1765-1773.

5. Kessing LV, Thomsen AF, Mogensen UG, Andersen PK. Treatment with antipsychotics and the risk of diabetes in clinical practice. $\mathrm{BrJ}$ Psychiatry. 2010; 197(4): 266-271.

6. Rummel-Kluge C, Komossa K, Schwarz S, et al. Head-to-head comparisons of metabolic side effects of second generation antipsychotics in the treatment of schizophrenia: a systematic review and meta-analysis. Schizophr Res. 2010; 123(2-3): 225-233.

7. Ulcickas Yood M, Delorenze GN, Quesenberry CP Jr, et al. Association between second-generation antipsychotics and newly diagnosed treated diabetes mellitus: does the effect differ by dose? BMC Psychiatry. 2011; 11 : 197.

8. Hasan A, Falkai P, Wobrock T, et al. World Federation of Societies of Biological Psychiatry (WFSBP) guidelines for biological treatment of schizophrenia, part 1: update 2012 on the acute treatment of schizophrenia and the management of treatment resistance. World J Biol Psychiatry. 2012; 13(5): 318-378.

9. Al-Zoairy R, Ress C, Tschoner A, Kaser S, Ebenbichler C. The effects of psychotropic drugs on the regulation of glucose metabolism. Curr Diabetes Rev. 2013; 9(5): 362-370.

10. Tschoner A, Engl J, Laimer M, et al. Metabolic side effects of antipsychotic medication. Int J Clin Pract. 2007; 61(8): 1356-1370.

11. Daumit GL, Goff DC, Meyer JM, et al. Antipsychotic effects on estimated 10-year coronary heart disease risk in the CATIE schizophrenia study. Schizophr Res. 2008; 105(1-3): 175-187.

12. Leucht S, Cipriani A, Spineli L, et al. Comparative efficacy and tolerability of 15 antipsychotic drugs in schizophrenia: a multipletreatments meta-analysis. Lancet. 2013; 382(9896): 951-962.

13. USA Food and Drug Administration. FDA approves new injectable drug to treat schizophrenia. 2015. http://www.fda.gov/ NewsEvents/Newsroom/PressAnnouncements/ucm465801.htm. Accessed April 12, 2018.

14. Meltzer HY, Risinger R, Nasrallah HA, et al. A randomized, doubleblind, placebo-controlled trial of aripiprazole lauroxil in acute exacerbation of schizophrenia. J Clin Psychiatry. 2015; 76(8): 1085-1090.

15. Nasrallah HA, Newcomer JW, Risinger R, et al. Effect of aripiprazole lauroxil on metabolic and endocrine profiles and related safety considerations among patients with acute schizophrenia. J Clin Psychiatry. 2016; 77(11): 1519-1525.

16. McEvoy JP, Risinger R, Mykhnyak S, et al. Durability of therapeutic response with long-term aripiprazole lauroxil treatment following successful resolution of an acute episode of schizophrenia. J Clin Psychiatry. 2017; 78(8): 1103-1109.

17. Weiden PJ, Du Y, Liu CC, et al. Switching stable patients with schizophrenia from their oral antipsychotics to aripiprazole lauroxil: a post hoc safety analysis of the initial 12 -week crossover period. CNS Spectr. 2018; 26: 1-7.

18. Croxtall JD. Aripiprazole: a review of its use in the management of schizophrenia in adults. CNS Drugs. 2012; 26(2): 155-183.

19. Kane JM, Sanchez R, Perry PP, et al. Aripiprazole intramuscular depot as maintenance treatment in patients with schizophrenia: a 52-week, multicenter, randomized, double-blind, placebocontrolled study. J Clin Psychiatry. 2012; 73(5): 617-624.

20. Peters-Strickland T, Baker RA, McQuade RD, et al. Aripiprazole once-monthly $400 \mathrm{mg}$ for long-term maintenance treatment of schizophrenia: a 52-week open-label study. NPJ Schizophr. 2015; 1: 15039.

21. McEvoy JP, Lieberman JA, Perkins DO, et al. Efficacy and tolerability of olanzapine, quetiapine, and risperidone in the treatment of early psychosis: a randomized, double-blind 52-week comparison. Am J Psychiatry. 2007; 164(7): 1050-1060.

22. Guo Z, L'Italien GJ, Jing Y, et al. A real-world data analysis of dose effect of second-generation antipsychotic therapy on hemoglobin A1C level. Prog Neuropsychopharmacol Biol Psychiatry. 2011; 35 (5): 1326-1332.

23. Potkin SG, Raoufinia A, Mallikaarjun S, et al. Safety and tolerability of once monthly aripiprazole treatment initiation in adults with schizophrenia stabilized on selected atypical oral antipsychotics other than aripiprazole. Curr Med Res Opin. 2013; 29(10): 1241-1251.

24. Kane JM, Peters-Strickland T, Baker RA, et al. Aripiprazole oncemonthly in the acute treatment of schizophrenia: findings from a 12week, randomized, double-blind, placebo-controlled study. J Clin Psychiatry. 2014; 75(11): 1254-1260.

25. Robinson DG, Gallego JA, John M, et al. A randomized comparison of aripiprazole and risperidone for the acute treatment of firstepisode schizophrenia and related disorders: 3-month outcomes. Schizophr Bull. 2015; 41(6): 1227-1236. 